Viewpoint

\title{
Planetary Health: A New Reality
}

\author{
Jonathan D. Salk ${ }^{1,2}$ \\ 1 Assistant Clinical Professor in Psychiatry, UCLA David Geffen School of Medicine, 11980 San Vicente Blvd., \\ Suite 810, Los Angeles, CA 90049, USA; jonathansalk1@gmail.com \\ 2 inVIVO Planetary Health, of the Worldwide Universities Network (WUN), West New York, NJ 10704, USA
}

Received: 26 December 2018; Accepted: 10 January 2019; Published: 16 January 2019

check for updates

\begin{abstract}
The grand challenges of our time-climate change, biodiversity losses, and global non-communicable disease rates-underscore that humanity and the planet are in crisis. Planetary health provides a unifying concept wherein efforts toward remediation and survival can be concentrated. Evidence derived from the animal kingdom and from human demography suggest that there is cause for optimism in planetary health. With proper navigation, a transition toward a new epoch-one of symbiotic flourishing-is possible. Responses to the current challenges can usher in a new reality, one in which the core value is the well-being of all. This paper presents the philosophies and perspectives of renown biophilosopher, Jonas Salk, who-after developing the first effective vaccine to prevent polio, one of the great achievements in public health-expanded his vision beyond the prevention of individual diseases to that of addressing the basic problems of humankind. This vision is very much in line with our current understanding of and approach to planetary health. In response to changing conditions, planetary limits, and evolutionary pressure, new values, new communities, and new modes of interacting will likely emerge and be integrated with developments in science, technology, economics, the arts, and international relations, resulting in our survival and enhanced health and well-being.
\end{abstract}

Keywords: Planetary health; human evolution; sustainable futures; global population growth; long-range thinking; renewable energy use; interdependence; cooperation; integration; value systems; cultural shift

\section{Introduction}

We, humanity and the planet, are in crisis. We are at a crossroads both in our history and in the entire course of human evolution [1,2]. At stake is not just the future of our own species, but that of several millions of others. If there is a way out of our current dilemma, it lies in a unitary concept-planetary health-a concept which recognizes that human health and the health of the Earth's natural systems are inseparable [3,4]. The perspective and goal of planetary health subsumes, unifies, and organizes all of our efforts for survival.

More than 60 years ago, Jonas Salk, with the help of an entire nation, developed the first effective vaccine to prevent polio; it was one of the great achievements in the history of public health [5]. Soon thereafter, he expanded his vision beyond the prevention of individual diseases to that of addressing the basic problems of humankind. In doing so, he developed a philosophy and a perspective very much in line with our current understanding of and approach to planetary health [6].

In this short article, I will present one aspect of that perspective.

For millennia, the global population size has increased gradually. However, in the 19th and 20th centuries, with the remarkable advances in science, medicine, industry, agriculture, and technology, human disease has decreased; the average human lifespan has increased, and we are able to feed and shelter more human organisms than ever before. This has resulted in the familiar explosive acceleration in world population growth in the past 150 to 200 years (Figure 1) [7]. 


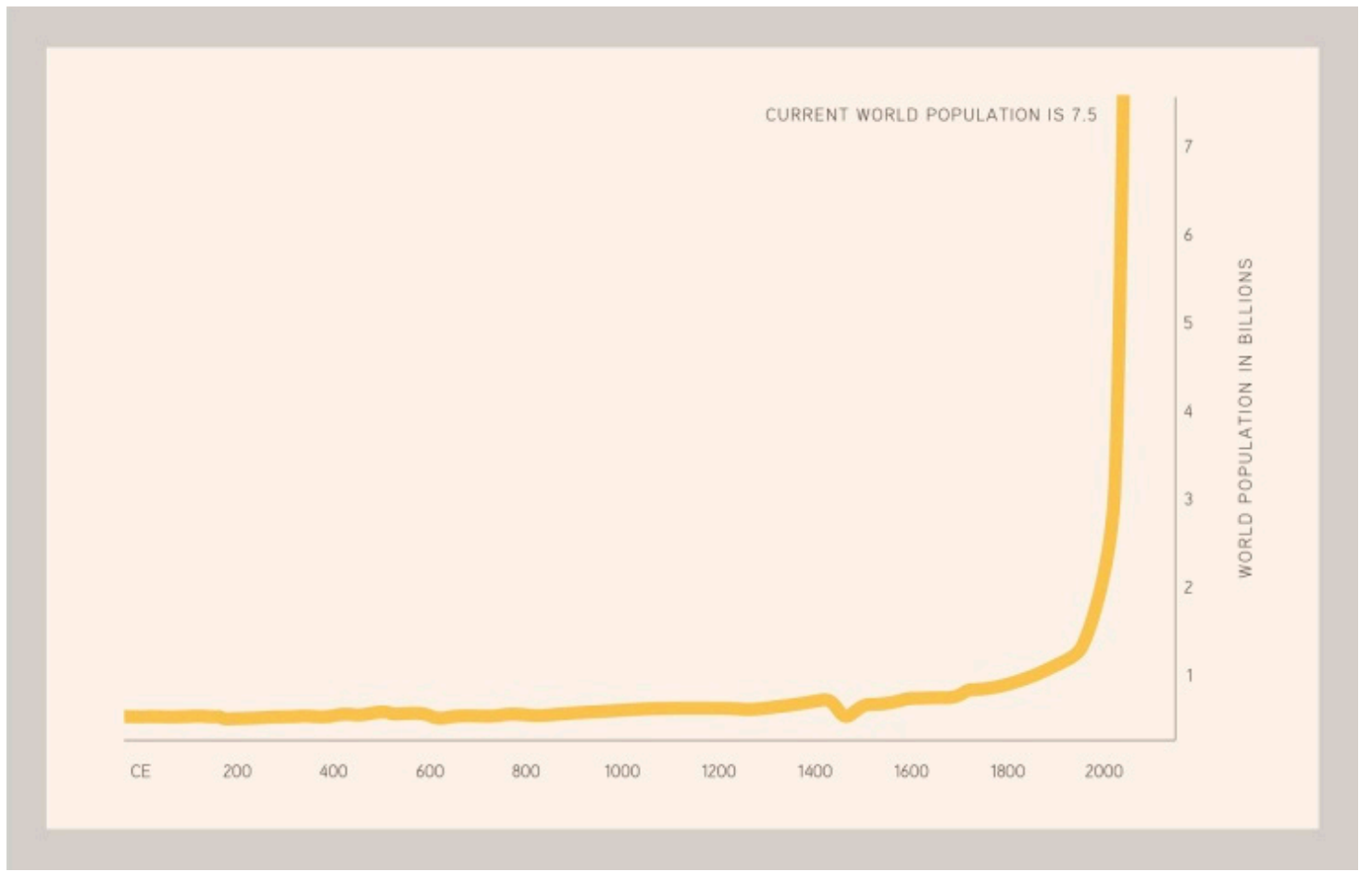

Figure 1. Changes in world population: From the beginning of the Common Era, the size of the human population grew gradually until about the 17th century and then with increasing speed through the 19th century. This gradual, but progressive acceleration was followed by a sudden steep rise in the 20th century - a consequence of the scientific, technological, industrial, and agricultural revolutions, which have had the effect of making it possible to sustain a human population far larger than ever before [7].

In the 1960's, Salk reasoned that this growth without limit could not continue and that, barring collapse, the population curve might assume a sigmoid shape (Figure 2) [7], similar to that of Raymond Pearl's classic experiment with fruit flies in a bottle [8-10].

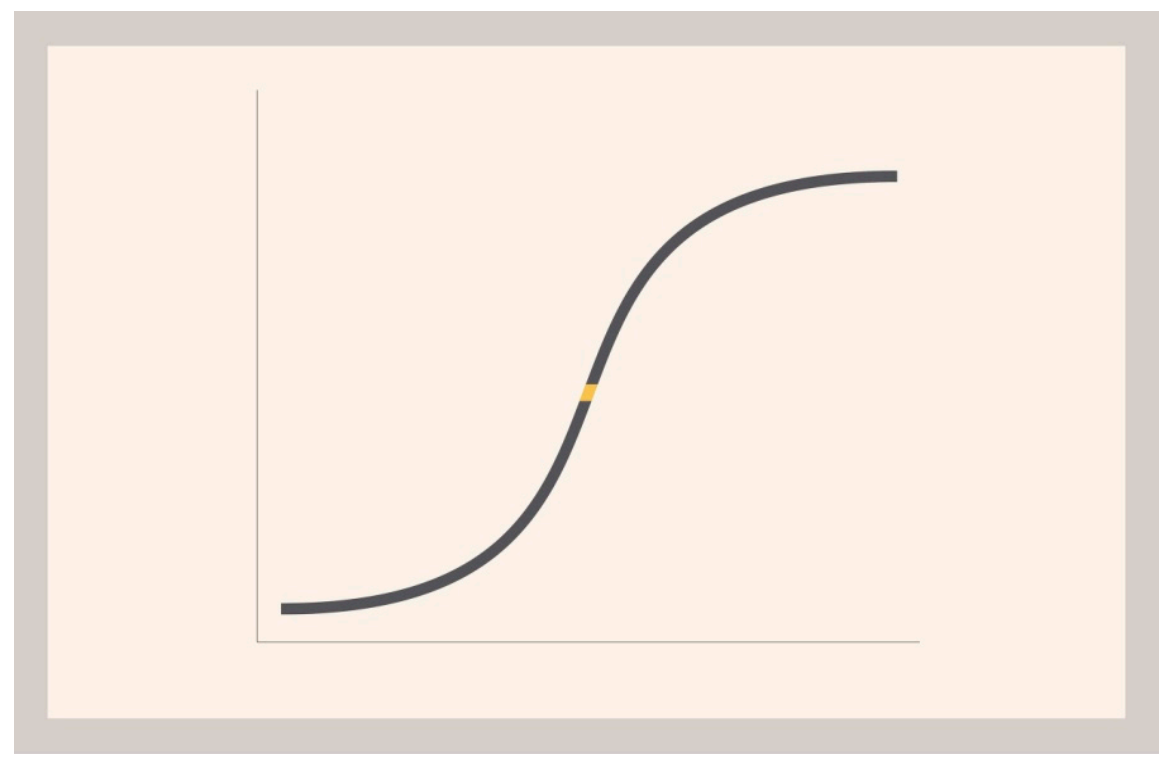

Figure 2. The sigmoidal pattern of population growth in a limited environment, as demonstrated in Raymond Pearl's classic experiment with fruit flies in a bottle. 
History and current projections bear this out. After tens of thousands of years of increase, growth rates began to decrease in the late 20th century [11], and an epochal point of inflection was passed. Worldwide population growth began slowing and, if current United Nations projections bear out, will plateau by the end of the current century (Figure 3) [12].

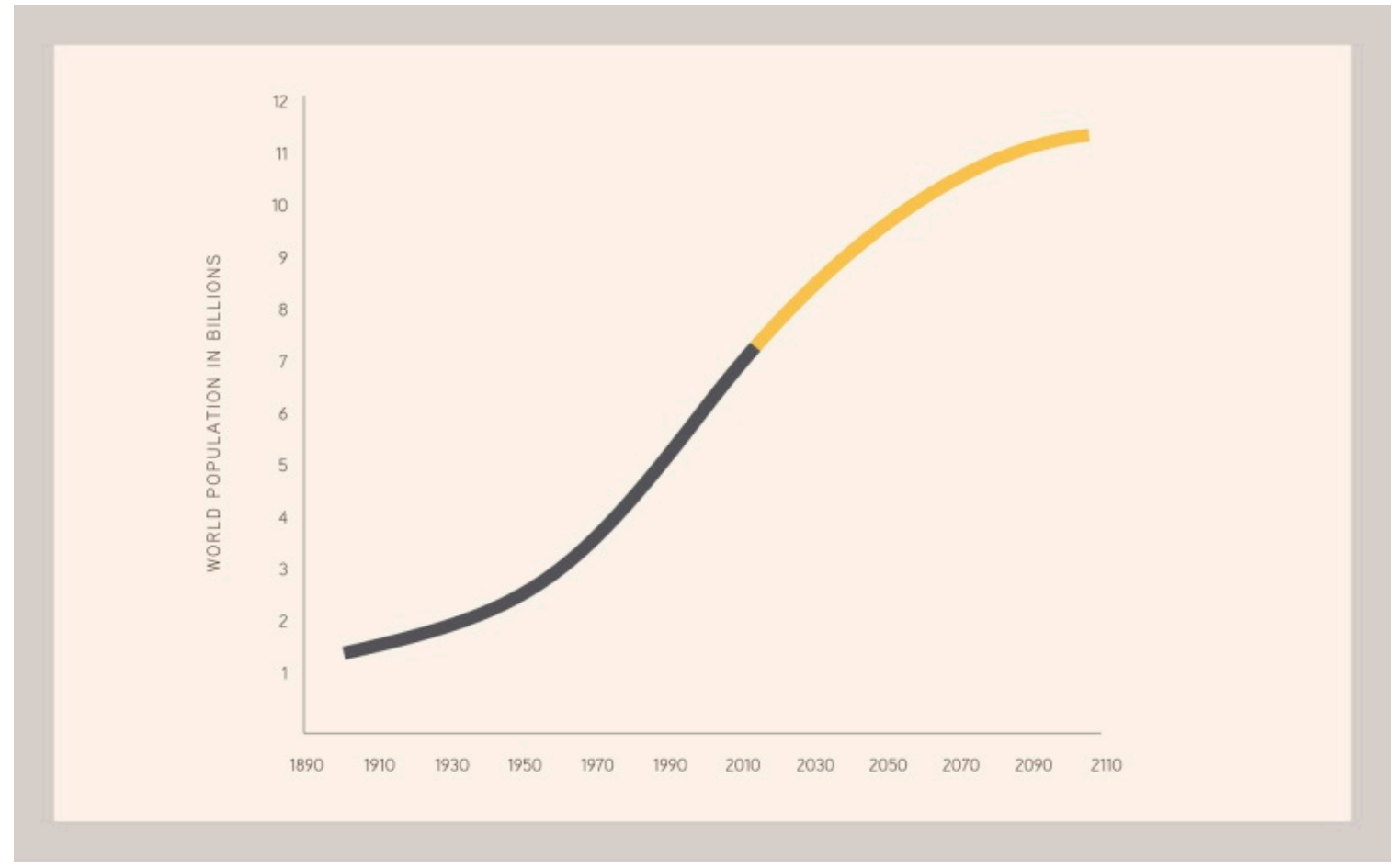

Figure 3. Projected plateau in world population growth based on median variant projections by the United Nations to 2100 [12]. This demonstrates the change from accelerating growth to decelerating growth. The inflection point of the curve was passed in the last decades of the 20th century, and humanity is currently in an age of slowing growth, one that may be very different, in terms of environmental limits and human social interactions, from the previous periods.

The reason that growth is slowing is one of the great stories in public health. With increasing levels of health, decreased infant mortality, and improvements in education and status of women, all in the context of sustainable socio-economic development, individuals decide to have fewer children per family, and population growth slows. Thus, the promotion of individual and societal health worldwide not only influences the quality of life of individuals, it benefits the entire planet with the slowing of population growth - a true win-win situation.

Jonas Salk's thinking went a step further.

He abstracted the sigmoid curve, divided it at the point of inflection, and noted that it consists of two phases: An upward facing, accelerating curve he called Epoch A, and a downward facing, decelerating curve, called Epoch B [13] (Figure 4). 


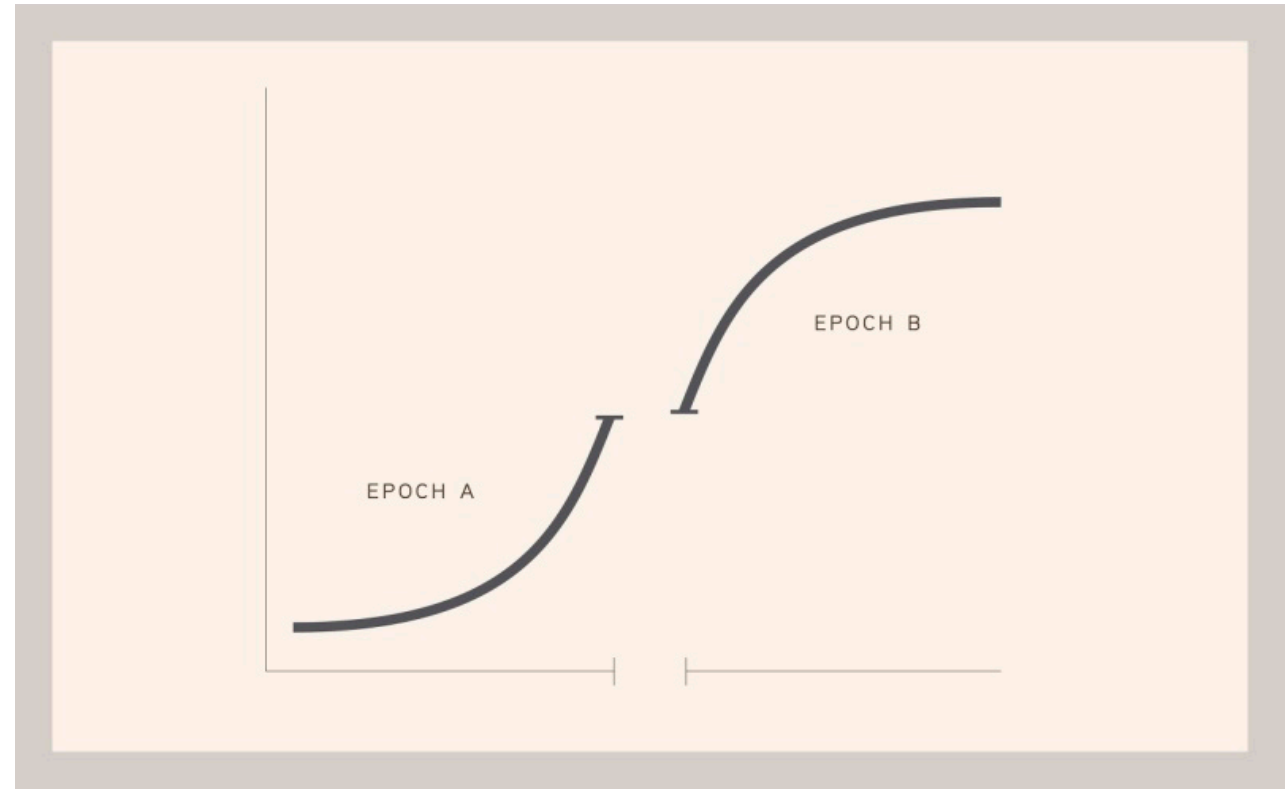

Figure 4. Phases of changing world population: An upward facing, accelerating curve Jonas Salk called Epoch A and a downward facing, decelerating curve, called Epoch B. To someone born in Epoch A, the future would appear to have few limitations in terms of growth, resources, and available energy. Someone living in Epoch B would however, have a distinct sense of limitations and the necessity to adapt to the approaching of a plateau in population growth. The difference in the shape of the curves implies that there will be fundamental qualitative differences in the nature of human life between the two Epochs.

The world looks very different to someone in Epoch A from how it appears to someone in Epoch B. In Epoch $\mathrm{A}$, there appear to be few limits and growth accelerates. In this era, emphasis is on fighting disease and on increasing the numbers of human beings. In Epoch B, where limits are apparent and we are approaching a plateau both in population growth and the consumption of resources, our focus shifts to the promotion of health, well-being, and the quality of each individual's life (Figure 5).

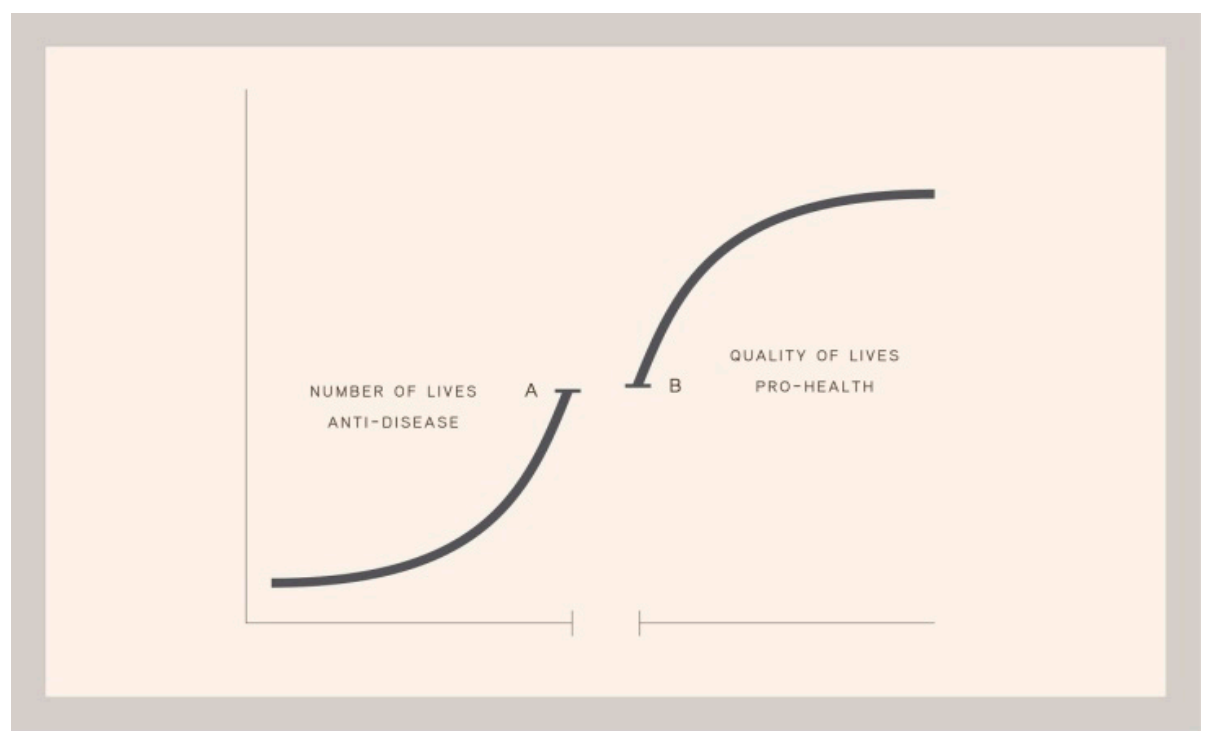

Figure 5. The shifting focus of values from 'fighting disease' to 'promoting health' with transition from population expansion to plateau in both population growth and the availability of resources. 
Between the two periods, there is also a difference in the predominant human values, attitudes, and behavior (Figure 6). In Epoch A, when there are few perceptible limits, values of unrestricted growth, expansion, and exploitation of both natural and human resources are rewarded with success and tend to predominate. Consumption, independence, and short-range thinking are most beneficial to the individual or group. In the different conditions of Epoch B, where resources are limited and growth is slowing, high value is placed on conservation, sustainability, interdependence, and long-range thinking.

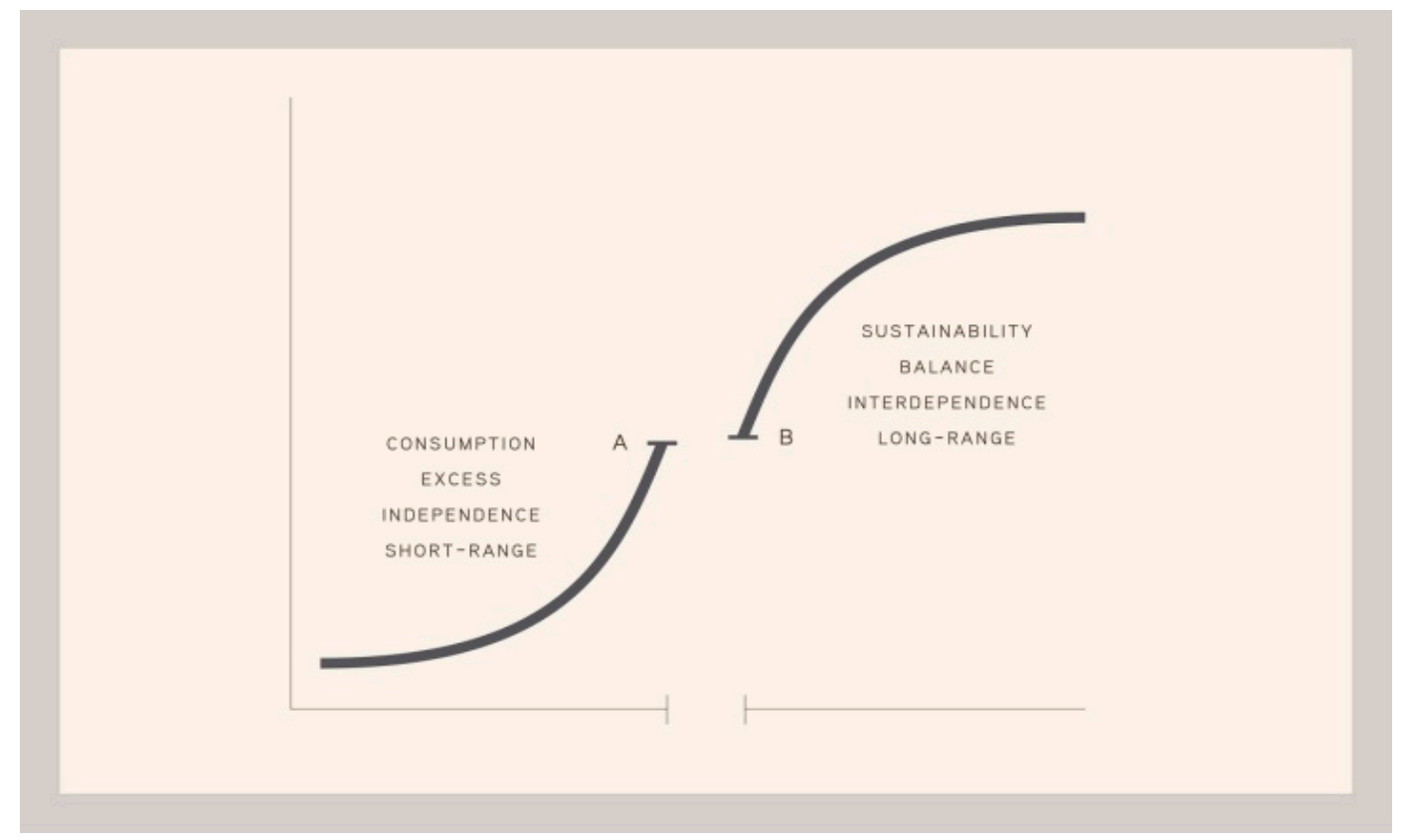

Figure 6. Shifting value systems with shifts in population dynamics. The attitudes, values, and behaviours that serve self-interest in Epoch A are very different from those that do so in Epoch B. Paradoxically, this means that in the reality of Epoch B, behaving in a more generous, community-oriented manner will better serve the interests of both individuals and groups than behaving in an exclusively self-oriented and competitive way. Therefore, collaboration, awareness of others, and balance will not be regarded as personal sacrifice. Instead, they will be personally and collectively beneficial.

What is remarkable about this shift is that it is likely to occur not because of what is morally right or wrong. If there is a shift, it will occur because the change is necessary for the survival of individuals, groups, and, ultimately, the entire species. Rather than coming as a response to some moral or ethical imperative, the transformation will come in response to evolutionary pressure and the need to adapt to changing conditions, something for which our species has shown a remarkable capacity through our evolution [11].

The point of transition between these epochs is a time of maximal conflict and tension. Since we are just passing the point of inflection, this explains much of the turmoil we see in human social and political life today. At this point, there is maximal pull between those who, faced with danger and uncertainty, look back and clamor to return to the values that worked in the past-use of fossil fuels, isolationism, competition, short-range, either/or thinking-and those who are looking forward to adopt values that will be adaptive to conditions in the present and future-renewable energy use, interdependence, cooperation and long range, both/and thinking.

The long-term perspective provided by the curve is useful in these turbulent and dangerous times. Looked at from the short-term (Figure 7), we seem to be mired in discord and chaos and headed toward disaster. 


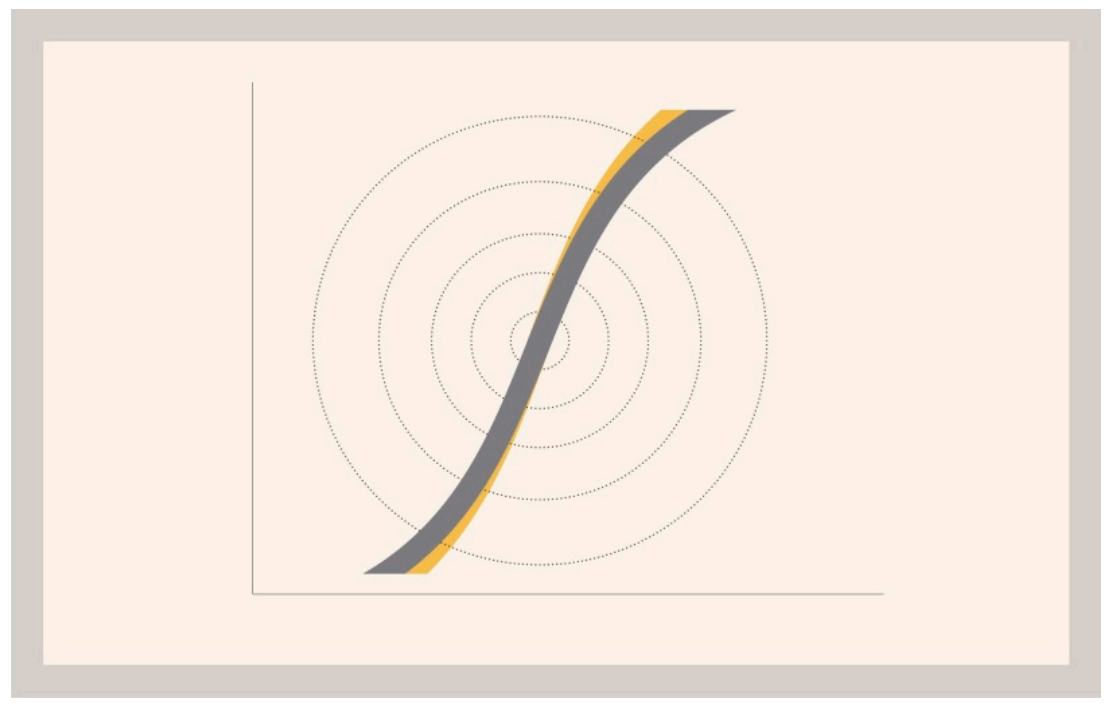

Figure 7. Short term perspective of tensions during global transitional periods. When viewed only from a short-term perspective, the tension and conflict inherent in the transition may seem chaotic and symptomatic of a disintegrating, collapsing world.

However, looked at from a longer perspective (Figure 8), we see that this conflict is part of an understandable and expected evolutionary or developmental process. In addition, there is a way forward to a potential positive outcome.

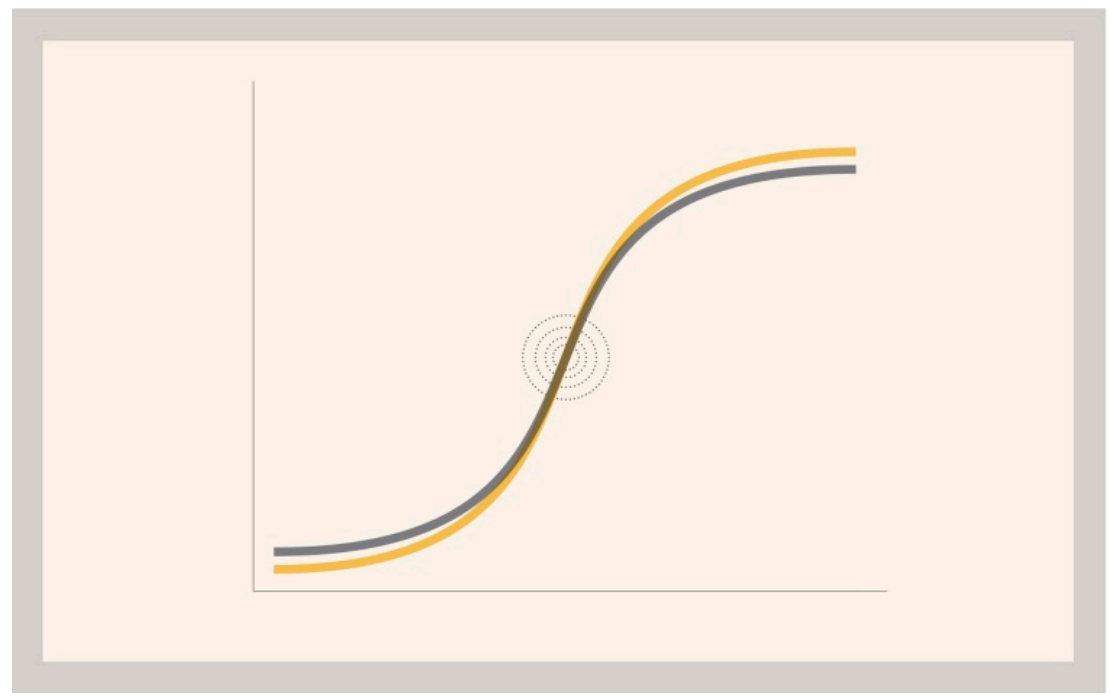

Figure 8. Long term perspective of global transitions. With a longer-range perspective, conflicts and uncertainties can be seen as part of an orderly if somewhat difficult process of nature. Looked at in this way, the disturbances of the present time may be seen not as a symptom of a disease that must be treated or eradicated, but as the result of the obsolescence of formerly successful patterns of life and the uncertain beginnings of new patterns appropriate to the emerging conditions.

The course of this transition is not predetermined. We face grave dangers and our behavior will determine our future. If we hold to values of rapid, sustained growth, unrestricted use of resources, and short-term thinking, there is a high likelihood that we will exceed the capacities of the planet to sustain human life and that of many other species. Furthermore, if we persist in either/or, win-lose, and short-range thinking, we risk a descent into disastrous conflict, decimating the human species and altering the entire ecosystem. 
If, however, we are able to make the transition to values that include limits, cooperation, long-term, both/and thinking, and an emphasis on well-being, we have the opportunity to enter a time in which we promote the health of every human being, of all species, and of the entire planet. That epoch can be one in which levels of human health and personal satisfaction will be higher than at any time in history.

We are at a point in the course of social evolution when the demands of survival converge with the highest aspirations of humankind. It is up to us to see that we navigate this transition successfully, emerging, and even flourishing, in a new reality, one in which the core value is the well-being of all.

This is the power of the concept of planetary health.

Funding: This work received no external funding.

Acknowledgments: Parts of this work were derived from the book by J. and J.D. Salk, A New Reality: Human Evolution for a Sustainable Future (City Point Press: Stratford, CT, USA, 2018; 256p; ISBN: 978-1-947951-04-4).

Conflicts of Interest: JDS has a trade book (above) which includes discussion of this topic. Any author's profits from sales of that book will be donated to the Jonas Salk Legacy Foundation.

\section{References}

1. Benatar, S.; Upshur, R.; Gill, S. Understanding the relationship between ethics, neoliberalism and power as a step towards improving the health of people and our planet. Anthropocene Rev. 2018. [CrossRef]

2. Kilpatrick, A.M.; Salkeld, D.J.; Titcomb, G.; Hahn, M.B. Conservation of biodiversity as a strategy for improving human health and well-being. Philos. Trans. R. Soc. Lond. Ser. B Biol. Sci. 2017, 372, pii: 20160131. [CrossRef] [PubMed]

3. Prescott, S.L.; Logan, A.; Albrecht, G.; Campbell, D.; Crane, J.; Cunsolo, A.; Holloway, J.W.; Kozyrskyj, A.L.; Lowry, C.A.; Penders, J.; et al. The Canmore Declaration: Statement of Principles for Planetary Health. Challenges 2018, 9, 31. [CrossRef]

4. Whitmee, S.; Haines, A.; Beyrer, C.; Boltz, F.; Capon, A.G.; de Souza Dias, B.F.; Ezeh, A.; Frumkin, H.; Gong, P.; Head, P.; et al. Safeguarding human health in the Anthropocene epoch: Report of The Rockefeller Foundation-Lancet Commission on planetary health. Lancet 2015, 386, 1973-2028. [CrossRef]

5. Salk, J. Landmark article Aug 6, 1955: Considerations in the preparation and use of poliomyelitis virus vaccine. By Jonas Salk. JAMA 1984, 251, 2700-2709. [CrossRef] [PubMed]

6. Prescott, S.L.; Logan, A.C. Down to Earth: Planetary Health and Biophilosophy in the Symbiocene Epoch. Challenges 2017, 8, 19. [CrossRef]

7. Salk, J. The Survival of the Wisest; Harper and Row: New York, NY, USA, 1973; ISBN 0-06-013738-X.

8. Salk, J. The world we will live in. Ann. N. Y. Acad. Sci. 1971, 184, 136-142. [CrossRef] [PubMed]

9. Salk, J.; Salk, J.D. World Population and Human Values: A New Reality; Harper and Row: New York, NY, USA, 1981; ISBN-13: 978-0060137786.

10. Pearl, R. The Biology of Population Growth; Ayre Company, Inc.: Riverdale, NY, USA, 1978; ISBN-13: 9780405104145.

11. Salk, J.; Salk, J.D. A New Reality: Human Evolution for a Sustainable Future; City Point Press: Stratford, CT, USA, 2018; 256p, ISBN 978-1-947951-04-4.

12. United Nations, Department of Economic and Social Affairs, Population Division. World Population Prospects: The 2017 Revision, Key Findings and Advance Tables; Working Paper No. ESA/P/WP/248; United Nations: New York, NY, USA, 2017.

13. Salk, J. The Survival of the Wisest. op. cit. p.18, Fig.10. Phi Delta Kappan 1975, 56, 667-669.

(C) 2019 by the author. Licensee MDPI, Basel, Switzerland. This article is an open access article distributed under the terms and conditions of the Creative Commons Attribution (CC BY) license (http://creativecommons.org/licenses/by/4.0/). 